\title{
Delineating northern peatlands using Sentinel-1 time series and terrain indices from local and regional digital elevation models
}

Martin Karlson, Magnus Gålfalk, Patrick Crill, Philippe Bousquet, Marielle Saunois and David Bastviken

The self-archived postprint version of this journal article is available at Linköping University Institutional Repository (DiVA):

http://urn.kb.se/resolve?urn=urn:nbn:se:liu:diva-160586

N.B.: When citing this work, cite the original publication.

Karlson, M., Gålfalk, M., Crill, P., Bousquet, P., Saunois, M., Bastviken, D., (2019), Delineating northern peatlands using Sentinel-1 time series and terrain indices from local and regional digital elevation models, Remote Sensing of Environment, 231, UNSP 111252.

https://doi.org/10.1016/j.rse.2019.111252

Original publication available at:

https://doi.org/10.1016/j.rse.2019.111252

Copyright: Elsevier

http://www.elsevier.com/

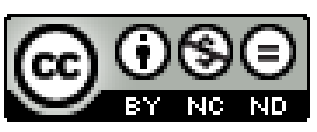


Delineating northern peatlands using Sentinel-1 time series and terrain indices from local and regional digital elevation models

Martin Karlson ${ }^{\mathrm{a}}$, Magnus Gålfalk ${ }^{\mathrm{a}}$, Patrick Crill ${ }^{\mathrm{b}}$, Philippe Bousquet ${ }^{\mathrm{c}}$, Marielle Saunois ${ }^{\mathrm{c}}$ and David Bastviken ${ }^{a}$

${ }^{\text {a }}$ Department of Thematic Studies - Environmental Change, Linköping University, 58183 Linköping, Sweden

${ }^{\mathrm{b}}$ Department of Geological Sciences, Stockholm University, 10691 Stockholm, Sweden

${ }^{\mathrm{c}}$ Laboratoire des Sciences du Climat et de l'Environnement (LSCE), Gif-sur-Yvette, France

\begin{abstract}
The spatial extent of northern peatlands remains highly uncertain in spite of rapidly developing satellite observation datasets. This is limiting progress in the understanding of fundamental biogeochemical processes, such as the global carbon (C) cycle and climate feedback effects on $\mathrm{C}$ fluxes.
\end{abstract}

In this study, we evaluated the capabilities of two new satellite datasets that enable regional scale mapping of peatland extent, including Sentinel-1 synthetic aperture radar (SAR) and the Arctic digital elevation model (ArcticDEM). Terrain indices and temporal features derived from these datasets provided input to Random Forest models for delineating four main land cover classes (forest, open upland, water and peatland) in an area in northern Sweden consisting of both lowland and mountainous terrain. The contribution of ArcticDEM to the classification accuracy was assessed by comparing the results with those derived when a high quality LiDAR based DEM (LiDEM) was used as alternative model input.

This study shows that multi-seasonal SAR alone can produce reasonable classification results in terms of overall accuracy $(\mathrm{OA} ; 81.6 \%)$, but also that it has limitations. The inclusion of 
terrain indices improved classification performance substantially. OA increased to $87.5 \%$ and 90.9\% when terrain indices derived from ArcticDEM and LiDEM, respectively, were included in the classification models. The largest increase in accuracy was achieved for the peatland class, which suggests that terrain indices do have the ability to capture the features in the geographic context that aid the discrimination of peatland from other land cover classes.

The relatively small difference in classification accuracy between LiDEM and ArcticDEM is encouraging since the latter provides circumpolar coverage. Thus, the combination of Sentinel-1 time series and terrain indices derived from ArcticDEM presents opportunities for substantially improving regional estimates of peatland extent at high latitudes.

\section{Key words}

Sentinel-1; satellite image time series; digital elevation model; Arctic DEM; terrain index; land cover mapping; wetland; peatland

\section{Introduction}

Wetlands are key environments for many biogeochemical cycles and provide several important ecosystem services (Millennium Ecosystem Assessment, 2005). For example, the common imbalance between primary production and decomposition makes wetlands store massive quantities of organic matter (Wieder and Vitt, 2006). Wetlands are also emitting large quantities of methane to the atmosphere (Kirschke et al. 2013) and therefore have profound implications for carbon and greenhouse gas balances (Kirschke et al., 2013; McGuire et al., 2009). Further, wetlands are also critical components in the hydrological cycle by regulating the regional water balance (Ireson et al., 2015) and influencing downstream water chemistry, with one example being the strong relationship between levels of dissolved humic substances and upstream peatland (Tockner et al., 2001). Hence, well-constrained areal estimates of different wetland types are critical for our knowledge about large-scale processes and 
ecosystem services, and about how these will change in a changing climate. However, the global extent of wetlands is still poorly constrained, with estimates of maximum annual extent ranging from 0.54 to $21.26 \times 10^{6} \mathrm{~km}^{2}$ (Hu et al., 2017; Melton et al., 2013). Particularly large uncertainties in the wetland extent have been estimated in northern latitude areas $\left(>60^{\circ} \mathrm{N}\right)$ where peatland is the main wetland type (Frey and Smith, 2007; Krankina et al., 2008; Pflugmacher et al., 2011).

Satellite remote sensing is arguably the only feasible alternative for regional scale wetland mapping and monitoring since it enables repeated coverage over large and inaccessible areas at low cost (Guo et al., 2017; Rundquist et al., 2001). Much progress in remote sensing-based mapping of wetland environments has been achieved in recent years following the improvement in sensing and data processing capabilities, and the theoretical understanding of the signal-target interaction (Ozesmi and Bauer, 2002; Silva et al., 2015). Both passive optical and active synthetic aperture radar (SAR) remote sensing systems have been proven capable of detecting and classifying wetland areas and dynamics in tropical, temperate and boreal areas (Bartsch et al., 2016; Corcoran et al., 2013; Hess et al., 2015; Reschke et al., 2012). While optical sensors mainly can discern spectral features of vegetation canopies and land cover, SAR microwaves interact with vegetation structural properties and can partly penetrate the canopy, depending on the wavelength used. This capability is of particular relevance in wetland types where standing water is often present under the vegetation cover.

At northern latitudes, active SAR systems have two main advantages over optical systems. They can penetrate the dense cloud cover commonly present during the short growing season and they are independent of solar radiation. However, satellite SAR systems have previously been limited by the lack of regular and long time series with regional coverage at high latitudes, as well as high data acquisition costs (Guo et al., 2017). In recent years, this situation has changed. Since 2014, the Sentinel-1A satellite of the European Space Agency 
(ESA) provides open access, high resolution C-band SAR data with global coverage. In 2016, Sentinel-1B accompanied its predecessor, which reduced the revisit time to less than 6 days at northern latitudes and thereby opened up new possibilities for SAR-based wetland mapping.

Many recent studies have demonstrated the improvements that can be achieved in the discrimination of wetland types when full polarimetric SAR (polSAR) systems are used, including C-band RADARSAT-2 and L-band ALOS-PALAR 2 (Brisco et al., 2011; de Almeida Furtado et al., 2016; Mahdianpari et al., 2017; White et al., 2015). Full polSAR enable reconstruction of the complete scattering matrix of the reflected SAR wave, from which polarimetric decompositions and descriptors can be calculated, and the contribution of different scattering mechanisms can be estimated. Such scattering mechanisms are related to different properties of wetlands, including vegetation type and water level. While the Sentinel-1 system has many benefits in terms of data availability, spatial coverage and temporal resolution, it is limited to a dual-polarized configuration with a lower potential to resolve subtle differences in the structure of wetlands and other land cover types. Several strategies to overcome this limitation have been explored, including the use of multiple wavelengths (Costa, 2004; Hess et al., 1995), dual or multi-seasonal data (Hess et al., 2015, 2003; Reschke et al., 2012; Widhalm et al., 2015) and multiple incidence angle acquisitions (Baghdadi et al., 2001). Out of these strategies, the use of dual or multi-season data has been deemed the most practically feasible and efficient approach for SAR based wetland mapping (Silva et al., 2015).

Improvements in the capability to detect wetlands and discriminate between wetland types can also be achieved by combining SAR with ancillary spatial datasets, including climate variables, spectral reflectance and topography (Corcoran et al., 2013; Töyrä and Pietroniro, 2005; Whitcomb et al., 2009). Topography is of particular interest because the formation and location of wetlands is highly dependent on local topographic features that control movement 
of water and sediment (Lang et al., 2013). Such topographic features, including slope, curvature, relative topographic position, local elevation variability, local relief and landscape roughness, can be computed from digital elevation models and are then referred to as indices. Several studies have shown that the inclusion of terrain indices (TI) in SAR based wetland mapping can improve the detection accuracy considerably. Most researchers have opted to use standard TI such as slope, whereas others have applied TI intended to represent the connection between topography and the presence of water in the landscape more realistically, including flow accumulation and steady-state topographic wetness index (Ågren et al., 2014; Higginbottom et al., 2018).

A main constraint for regional scale application of TI in mapping at northern latitudes has been the absence of a freely available, high quality and high resolution DEM. The DEM closest to fulfill these criteria is the Shuttle Radar Topography Mission (SRTM) global DEM, but it does not cover areas above $60^{\circ}$ north latitude. However, the release of the ArcticDEM by the Polar Geospatial Institute in late 2017 , which provide freely available pan-Arctic elevation data at $2 \mathrm{~m}$ (strip-mode) and $5 \mathrm{~m}$ (mosaic-mode) spatial resolution opened up new possibilities for improving the mapping of northern latitude wetlands by combining regional scale SAR and DEM data.

The aim of this study was to evaluate the capability of Sentinel-1 C-band SAR to map land cover, including peatlands and inland water embedded in both lowland and mountainous terrain, in a high latitude region of Northern Sweden, and to investigate the potential improvements in classification accuracy that can be achieved by the inclusion of a high resolution DEM. The study focused on four main questions.

i) Can multi-seasonal SAR data alone produce accurate land cover maps?

ii) To what extent do the inclusion of terrain indices improve the classification accuracy? 
iii) Is the ArcticDEM a useful alternative to a DEM derived from light detection and ranging (LiDAR)?

iv) Which are the most important predictor variables derived from SAR and DEM data for accurate classification of the land cover classes peatland, forest, inland water, and open upland?

\section{Material and methods}

\subsection{Study area and target land classes}

The study area $\left(24924 \mathrm{~km}^{2}\right)$ is located in northern Sweden and stretches from Jokkmokk in the south to the lake Torneträsk in the north (Fig. 1). The elevation ranges from $43.8-2070 \mathrm{~m}$ above sea level. Mean annual precipitation and temperature (Swedish Meteorological and Hydrological Institute; www.smhi.se; during the reference period 1960-1990) ranged from 400 to $1400 \mathrm{~mm}$ and from 0 to $-3{ }^{\circ} \mathrm{C}$, respectively, across the area. The snow-covered season extends from October to May (175-225 days per year). The coverage of the Swedish national high-resolution DEM, as of November 2017, and the extent of the Sentinel-1 scenes defines the western and eastern boundaries of the study area (Fig. 1). This area was selected based on availability of ancillary datasets (i.e. DEM and reference data), and the possibility to cover a wide variety of land cover types representative of both lowland and mountainous terrain. 


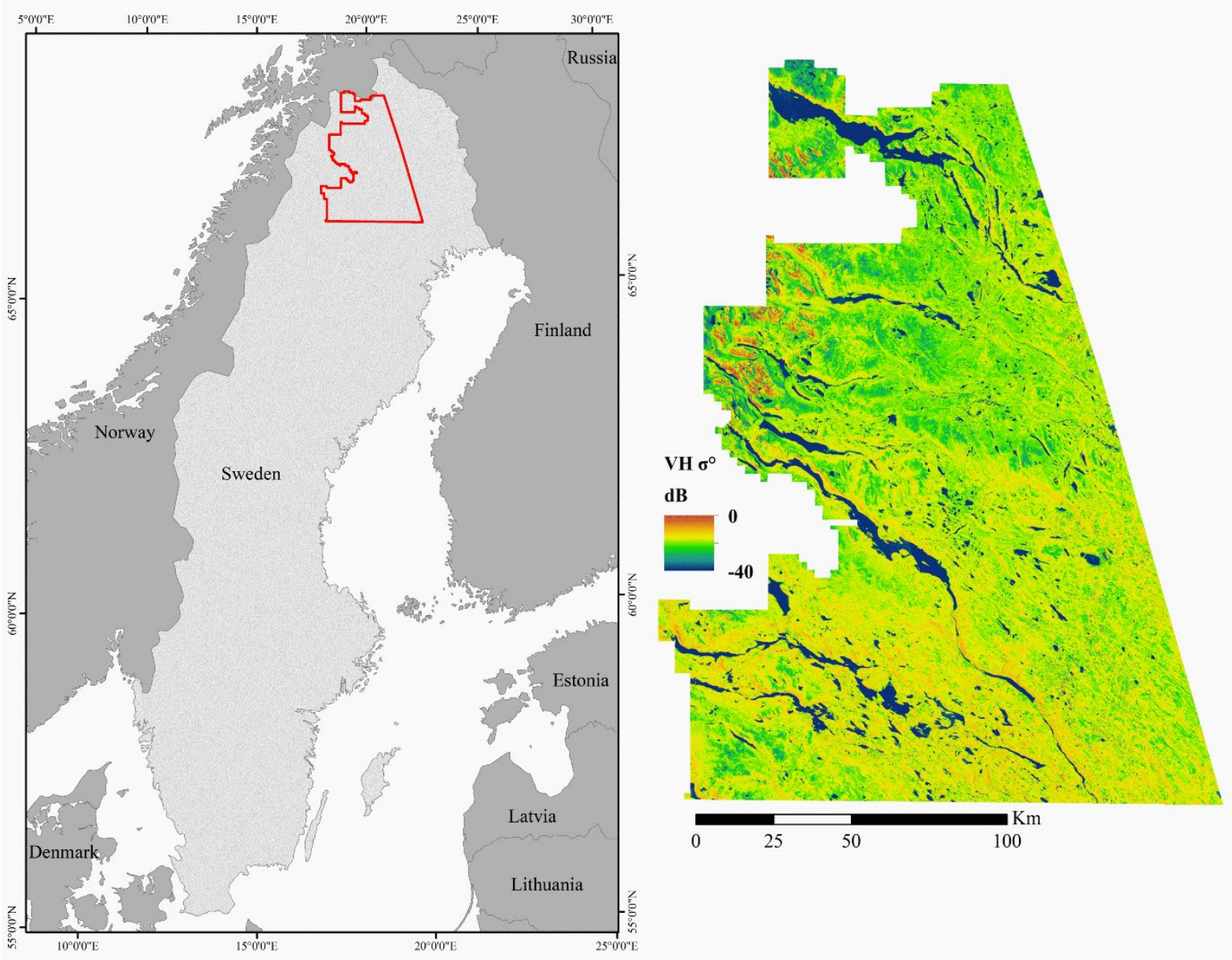

Figure 1. Left: Map showing the Nordic countries and the study area in northern Sweden.

Right: Sentinel-1 backscatter mosaic (VH polarization) of the study area on July 11, 2016.

The main land cover classes in the area include forest, open upland areas, peatland and inland water. The forest mainly consists of mountain birch (Betula pubescens). The open upland class includes areas covered by low growing graminoid, forb and shrub species, as well as areas with boulders, gravel and exposed bedrock. Inland water includes rivers, lakes, ponds and reservoirs. According to the national land cover map produced by the Swedish National Land Survey (Lantmäteriet, 2015a), the peatland class has three sub-categories, including i) normal open peatland, ii) inaccessible peatland and iii) forested peatland. The peatland subcategories areal extent and spatial characteristics are described in Table 1. Normal open peatland is the most common type in the study area. It is composed of bogs and fens with a 
tree and shrub cover less than $30 \%$ and is generally walkable. Inaccessible peatlands are also composed of bogs and fens with a tree/shrub cover below 30\% but are generally wetter compared to the normal open class and has a higher propensity to be flooded. Forested peatlands have a tree cover above $30 \%$ and are normally small, elongated boundary features located on the edges of the two other peatland classes. The forested peatland class is most abundant in the southern parts of the study area where the tree cover is generally denser compared to the central and northern parts. Mean peat depth and annual peat growth in northern Sweden is $1.52 \mathrm{~m}$ and 0.3-0.4 $\mathrm{mm} \mathrm{yr}^{-1}$ (Franzén, 1985).

Table 1. Descriptive statistics of peatland sub-categories.

\begin{tabular}{lllll}
\hline Peatland & Mean & Length-to- & Proportion of & Peatland \\
type & size (ha) & width ratio & study area (\%) & proportion (\%) \\
\hline Normal, open & 7.7 & 2.09 & 13 & 75 \\
Inaccessible & 19.9 & 2.02 & 4 & 20 \\
Forested & 0.8 & 9.10 & 1 & 5 \\
\hline
\end{tabular}

\subsection{Data}

\subsubsection{Sentinel-1 time series}

Sentinel-1 data from the year 2016 (Table 2) were acquired from the ESA Scientific hub website (https://scihub.copernicus.eu/dhus/) as full resolution ground range detected (GRD) products collected in ascending passes and interferometric wide swath mode. The GRD product is based on focused SAR data that has been detected, multi-looked and projected to ground range. All data were acquired in C-band dual polarization, including vertically transmitted and vertically received (VV), and horizontally transmitted and vertically received 
(VH). Two Sentinel-1 scenes for each acquisition date from the same relative orbit (131) cover the extent of the study area.

Table 2. Sentinel-1 acquisitions

\begin{tabular}{lll}
\hline $\begin{array}{l}\text { Acquisition } \\
\text { date }\end{array}$ & Incidence angle north & Incidence angle south scene \\
scene & \\
\hline 160113 & $30.341-45.623$ & $30.412-45.677$ \\
160325 & $30.352-45.630$ & $30.422-45.682$ \\
160605 & $29.625-45.769$ & $29.705-45.856$ \\
160711 & $29.625-45.769$ & $29.705-45.855$ \\
160816 & $29.625-45.769$ & $29.706-45.856$ \\
160909 & $29.623-45.769$ & $29.703-45.855$ \\
160921 & $29.622-45.794$ & $29.701-45.854$ \\
161003 & $29.620-45.793$ & $29.699-45.853$ \\
\hline
\end{tabular}

\subsubsection{LiDAR DEM (LiDEM)}

The Swedish national $2 \mathrm{~m}$ DEM is produced from airborne LiDAR (LiDEM) and represents the bare Earth surface where natural and built features (e.g., trees and buildings) have been filtered out. The mean elevation error is estimated to be $<0.5 \mathrm{~m}$ (Lantmäteriet, 2015b). The LiDEM was resampled into a $10 \times 10 \mathrm{~m}$ grid using bilinear interpolation to enable integration with the SAR data and to reduce the data volume.

\subsubsection{ArcticDEM}

ArcticDEM is produced from in-track, optical high-resolution imagery collected by the Digital Globe constellation of satellites, in particular WorldView 1-3, using stereo auto- 
correlation techniques on overlapping images. This is a digital surface model that captures the natural and built features of the Earth surface. Version 2.0 of the product was acquired as mosaiced DEM files distributed in $50 \times 50 \mathrm{~km}$ tiles at $5 \mathrm{~m}$ spatial resolution. The ArcticDEM was also resampled into a $10 \times 10 \mathrm{~m}$ grid using bilinear interpolation for integration with the SAR data. Version 2.0 of ArcticDEM is partly affected by clouds and missing scan-lines, which resulted in approximately 10 percent of the study area having no data values. To account for this, the data coverage of ArcticDEM was used to mask the Sentinel-1 and LiDAR datasets, as well as the reference data described below.

\subsection{Reference data}

Two sources provided references data, including color ortho-imagery (GSD-ortofoto) and a land cover map (GSD-terrain map), both produced by the Swedish National Land Survey. The ortho-imagery is a mosaic consisting of aerial photos acquired during a period between 2008 and 2016, with a spatial resolution of $0.5 \mathrm{~m}$ and an estimated mean geometric error of $1 \mathrm{~m}$ (Lantmäteriet, 2015c). The land cover map is a 1:500000 product developed from visual interpretation of stereo aerial imagery with a mean geometric error of $10 \mathrm{~m}$ and a minimum mapping unit of 0.6 ha (Lantmäteriet, 2015a). The timing of the land cover map depends on the Swedish national program for acquiring aerial imagery, and consequently varies between 2008 and 2016 in the study area. These two reference datasets were used in combination to derive training and validation data as described below. The ortho-imagery provided a means to account for potential errors in the reference land cover map.

We conducted an initial assessment of the three peatland sub-categories to determine the feasibility of distinguish them based on multi-seasonal Sentinel-1 backscatter and terrain indices. Due to the small size and elongated shape of forested peatlands relative to the pixel size of the DEM and Sentinel-1 data $(10 \times 10 \mathrm{~m})$, these were merged with their neighboring peatland objects. The forested peatlands that did not share a border with another peatland 
object were included in a general peatland class. The two other peatland classes in the reference land cover map are both bog-fen complexes where the delimiting factors are accessibility and propensity to be flooded. These two classes do have slightly different backscatter responses, especially after snowmelt when the inaccessible peatlands tend to produce lower backscatter values due to higher water saturation. However, the backscatter variability within these classes is high relative to differences in their mean values. A similar pattern can be seen for the terrain indices. Due to the imprecise definitions of the peatland classes and similarities in backscatter responses and terrain indices, we choose to merge them into a general peatland class.

\subsubsection{Training data}

For each class, training polygons were delineated by visual interpretation in both lowland and mountainous terrain using ortho-imagery and the land cover map as reference (Table 3). We set the minimum size of training polygons to $3 \times 3$ pixels, or 0.09 ha. Open upland polygons included areas of rock, bare soil and open vegetated land without trees, in particular heathland. For the forest class, polygons were distributed in areas with different tree cover density and species composition to capture the variability in the study area. Most of the forest polygons were located in areas with mountain birch, which is the dominant forest type in the study area. The water class included areas of lakes, ponds and rivers. Training polygons for the peatland class were located in peatlands with different sizes. In addition, different sections of the peatlands (e.g., central parts or close to edges) were sampled to account for variations in topographic structure, vegetation composition and wetness.

Table 3. Classification training dataset.

\begin{tabular}{lll}
\hline Land cover class & No. polygons & Mean area (ha) \\
\hline Open upland & 242 & 1.88
\end{tabular}




\begin{tabular}{lcc} 
Forest & 220 & 0.59 \\
Water & 199 & 1.54 \\
Peatland & 187 & 0.68 \\
\hline All classes & 848 & 1.17 \\
\hline
\end{tabular}

\subsubsection{Validation data}

An independent validation dataset was assembled by randomly distributing 3000 vector points, each representing an individual pixel, throughout the study area (Table 4). The land covers of the corresponding pixels were then determined through visual comparison with the reference datasets. The frequency distribution of the validation pixels was comparable to the area distribution of the classes in the reference land cover map.

Table 4. Validation dataset.

\begin{tabular}{ll}
\hline Land cover class & No. pixels \\
\hline Open upland & 1152 \\
Forest & 770 \\
Water & 370 \\
Peatland & 708 \\
\hline Total & 3000 \\
\hline
\end{tabular}

\subsection{Pre-processing and predictor data sets}

\subsubsection{SAR predictors}

Prior to classification, SAR imagery was pre-processed using the Sentinel Application

Platform (SNAP) software (ESA, 2017). Thermal noise removal was first performed and the 
SAR intensity data was then calibrated to backscatter coefficient $\left(\sigma^{\circ}\right)$. A $5 \times 5$ median speckle filter was applied to reduce noise, while preserving edges of landscape features. The calibrated and speckle filtered SAR data underwent Range-Doppler terrain correction (producing $10 \times 10 \mathrm{~m}$ pixels) to compensate for topographical distortions using the 1 arc sec ASTER global DEM automatically downloaded by SNAP, and was re-projected to Universal Transverse Mercator (UTM) zone $34 \mathrm{~N}$. The backscatter coefficient $\sigma^{\circ}$ was then remodeled to decibel $(\mathrm{dB})$ scale using parameters provided in the accompanying metadata. The two scenes from each date were mosaicked using bilinear interpolation as resampling method. SAR predictors for the Random Forest classification models included VH and VV polarizations from the eight dates presented in Table 2.

\subsubsection{Terrain indices}

The software Whitebox Geospatial Analysis Tools 3.4 (Lindsay, 2016) provided tools to derive terrain indices characterizing landscape position and relief, which can be indicative of water-collecting terrain (Wright and Gallant, 2007), including locations where wetlands are often formed. A total number of 10 terrain indices were used in the study (Table 5). Two window sizes, $7 \times 7$ and $30 \times 30$ pixels, were used for the calculation of difference from mean elevation (DIF), deviation from mean elevation (DME) and standard deviation of elevation (SDE). These window sizes reflect the general size and shape characteristics of wetland patches in the study area.

DIF quantifies the difference between the central grid cell and the mean elevation within a moving window. DME is similar to DIF, but is normalized by the standard deviation within the window. Both DIF and DME provides a measure of topographic position relative the surrounding area. SDE is the standard deviation within a defined window and provides a measure of local surface roughness. The multi-resolution elevation residual index (MERI) also characterizes the topographic position, but does this across a range of spatial scales. The 
MERI algorithm calculates DIF in a series of window sizes from $3 \times 3$ to a maximum window size $\left(r_{\max }\right)$ that depend of the size of the DEM;

$$
\mathrm{r}_{\max }=\text { floor }\left(\log _{\mathrm{B}}(\min (\mathrm{C} / 2, \mathrm{R} / 2))\right)
$$

where $\mathrm{B}$ is the base value (default 1,5 ) defining the density of sampled scales, and $\mathrm{C}$ and $\mathrm{R}$ represents columns and rows in the DEM, respectively. MERI quantifies the proportion of tested scales where central grid cell has a higher value compared to the mean elevation.

The local topographic relief (TRI) was calculated from the root-mean-square-deviation between the central pixel and its neighbor pixels. Slope was derived using the finite difference method of Horn (1981) within a $3 \times 3$ moving window and the clock-type grid number scheme developed by Gallant and Wilson (2000). In addition to being used as an independent index, slope was also used a input to the wetness index (WI; Beven and Kirby 1979). The wetness index (WI) quantifies the propensity of a site (pixel) to accumulate water as a function of its upslope contributing area (As) and local slope,

$$
\mathrm{WI}=\operatorname{Ln}(\text { As } / \tan (\text { slope }))
$$

where As was derived using the D8 algorithm (O'Callaghan and Mark, 1984).

Table 5. Terrain indices derived from LiDEM and ArcticDEM.

\begin{tabular}{lll}
\hline Terrain index & Window size (pixels) & Reference \\
\hline Deviation from mean & $7 \times 7$ and $30 \times 30$ & (Gallant and Wilson, 2000) \\
elevation (DME) & \\
Difference from mean & $7 \times 7$ and $30 \times 30$ & (Gallant and Wilson, 2000) \\
elevation (DIF) & &
\end{tabular}


index (MERI)

Standard deviation of

$7 \times 7$ and $30 \times 30$

(Gallant and Wilson, 2000)

elevation (SDE)

Slope (SLP)

N/A

(Gallant and Wilson, 2000;

Horn, 1981)

Topographic ruggedness

$7 \times 7$ and $30 \times 30$

(Riley et al., 1999)

index (TRI)

Wetness index (WI)

N/A

(Beven and Kirby, 1979)

\subsection{Random Forest classification}

A robust regional scale peatland mapping at high spatial resolution requires a computationally efficient classification method that does not depend on assumptions about data distribution and can account for nonlinear relationships between input variables. In addition, the use of high-resolution multi-seasonal SAR data and terrain indices can potentially result in very large data volumes. It is therefore important that the classification method enable assessments of the importance of the input variables, which can facilitate substantial data volume reductions and processing requirements. The Random Forest (RF; Breiman, 2001) classifier fulfills these requirements and has been used successfully for wetland mapping in several studies (Clewley et al., 2015; Corcoran et al., 2013; de Almeida Furtado et al., 2016; Whitcomb et al., 2009).

The RF classification algorithm was selected in this work since it is computationally efficient, easy to parameterize, accurate, stable and enables practical means to rank predictors based on their influence on the classification (Belgiu and Drăguţ, 2016; Karlson et al., 2016; Pelletier et 
al., 2016). In addition, several recent studies have demonstrated the suitability of RF for classifying land cover in subarctic landscapes using multi-source remote sensing data (Amani et al., 2017; Mahdianpari et al., 2017; Torbick et al., 2012). The two main parameters in RF are the number of classification trees (ntree) and the number of predictors to be considered at each tree node (mtry). In this study, ntree was set to 1000 , whereas mtry was set to the default value of the square root of the total number of predictors (Breiman, 2001). We based the ntree parameter selection on observed changes in the internal bootstrapping estimate of accuracy when successively increasing ntree by 100, and this estimate stabilized after including 1000 trees in the classification model. RF was implemented in the "RandomForest" R environment software package (Liaw and Wiener, 2002; R Development Core Team, 2013).

Separate classifications using three different classification models enabled comparisons between the predictor datasets, and in particular to assess the influence of including terrain indices derived from the two high-resolution DEM. The classification models included i) multi-season SAR (SAR-only), ii) multi-season SAR and terrain indices from LiDEM (LiDEM+SAR), and iii) multi-season SAR and terrain indices from ArcticDEM (ArcticDEM+SAR). Each of the three resulting land cover maps were regularized to remove spurious effects of SAR speckle using a majority filter with a square kernel of $5 \times 5$ pixels.

\subsection{Accuracy assessment}

Statistical accuracy assessments were calculated for all three classification models using the 3000 validation points to construct confusion matrices. Standard accuracy indicators were estimated from the confusion matrices, including overall accuracy (OA), Kappa statistic (Cohen, 1960), and the class specific User's and Producer's accuracy. Kappa statistic is a measure of overall accuracy that takes into account the possibility that agreements occur by chance. User's accuracy is a measure of class reliability derived from the fraction of correctly classified pixels in relation to all pixels classified as this class in the map. Producer's accuracy 
is the fraction of correctly classified pixels with regard to all pixels of a particular class in the validation dataset.

We also performed an assessment to identify the size of smallest peatland object that can be reliably identified (i.e., minimum mapping unit; MMU) by the classification method. The peatland objects in the reference land cover map were grouped into size classes, which formed the unit of the assessment (Table 6). The proportion of correctly classified pixels within each peatland object was then calculated and aggregated at size class level.

Table 6. Size classes of reference peatland objects.

\begin{tabular}{llll}
\hline Size class (ha) & No. objects & Mean size (ha) & $\begin{array}{l}\text { Proportion of peatland class } \\
\mathbf{( \% )}\end{array}$ \\
\hline $0.6-1$ & 5645 & 0.88 & 1.4 \\
$1-3$ & 11167 & 1.94 & 6.4 \\
$3-5$ & 3566 & 4.19 & 4.5 \\
$5-10$ & 3280 & 7.71 & 7.5 \\
$10-20$ & 1906 & 15.32 & 8.7 \\
$20-50$ & 1331 & 34.56 & 13.3 \\
$50-100$ & 434 & 75.59 & 9.8 \\
$100-200$ & 250 & 152.14 & 11.2 \\
$200-500$ & 132 & 346.90 & 13.7 \\
$>500$ & 67 & 1263.47 & 23.5 \\
\hline Total & 27778 & 11.1 & 100 \\
\hline
\end{tabular}

To improve the understanding of the classification procedure, we also assessed the influence of the individual predictors on the separation of the four land cover classes. We applied a sequence where a random sample $(60 \%)$ of the training dataset was used to construct a RF. The "out of bag" data was used to rank the predictors based on the mean decrease in accuracy (MDA) criterion (Corcoran et al., 2013; Karlson et al., 2015), which quantify the relative change in accuracy that results from including or excluding a particular predictor in the classification (Breiman, 2001). This sequence was repeated 100 times and the MDA scores were then averaged to produce the final predictor ranking. 


\section{Results and discussion}

This study provides insights into the potential of two new spatial datasets with high resolution, Sentinel-1 and ArcticDEM, for mapping northern latitude land cover on a regional scale. The focus was on the delineation of peatland areas due to their important role in the global water and carbon cycles, and previous difficulties to estimate their extent in northern latitude areas. However, the results are relevant also for the other included land classes.

\subsection{Classification using multi-season SAR}

Linear intensity channels $\left(\sigma^{\circ} \mathrm{VH}+\sigma^{\circ} \mathrm{VV}\right)$ from the eight dates (Table 1$)$ were first used in isolation to assess the capability of Sentinel-1 to classify major land cover on regional scale. Results indicated that relatively high overall accuracy $(81.6 \%)$ could be achieved in this type of environment (Fig. 2). Previous efforts using C-band SAR for classifying similar land cover have reported comparable overall accuracies. For example, Baghdadi et al. (2001) achieved an overall accuracy of $76 \%$ using single date VH backscatter. Furthermore, Merchant et al. (2017) reported an overall accuracy of 77\% using single date RADARSAT backscatter. Higher overall accuracies ( $>85 \%$ ) have been reported, but most of these cases used multipolarimetric systems (Merchant et al., 2017; White et al., 2015) with limitations in geographic coverage. While multi-polarometric approaches are not possible with Sentinel-1 imagery, our results show that relatively high accuracies can be achieved if multi-season image acquisitions are used. 


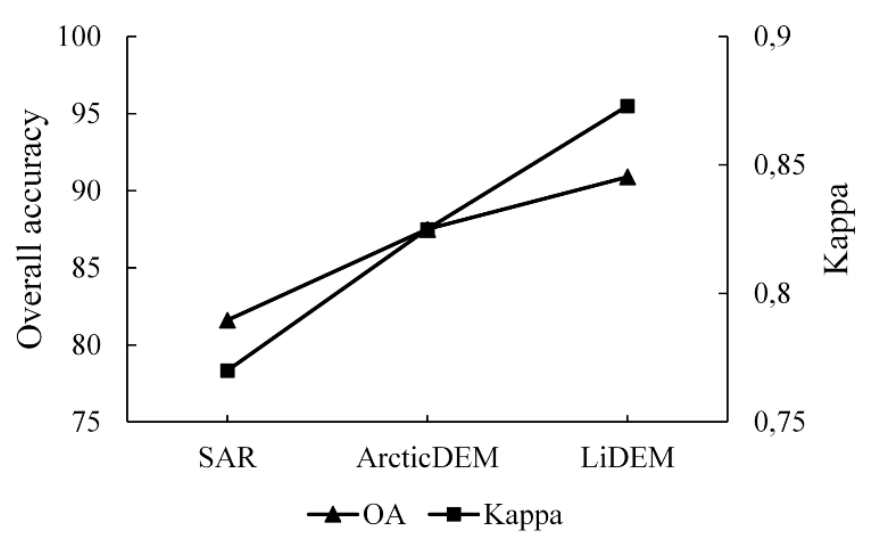

Figure 2. Overall classification accuracy (\%) and Kappa statistic values produced by three classification models.

The confusion matrix (Table 7) show highly variable class specific accuracies for the SARonly classification model. Open upland was classified relatively accurately considering that it is an aggregated class that includes rather contrasting land cover, in particular heath and rock outcrop. On the other hand, the SAR-only model had problems to distinguish the peatland class, which was frequently confused with open upland. This was expected since both these classes are generally characterized by a plain surface producing similarly low backscatter in the SAR imagery throughout the year. In addition, near-surface soil moisture strongly control backscatter from peatlands (Baghdadi et al., 2001) and large spatial variations due to the size and highly variable elevation of the study area may introduce noise in the classification model, making it especially problematic to separate relatively dry peatlands from open uplands. Some confusion also occurred between the peatland and forest classes. Confusion is likely because the forest canopy cover differs considerably in the region, whereas dense shrub vegetation often occupy wetland edges, which increases the canopy scattering to a level that overlaps that of the forest class (Merchant et al., 2017). A part of this confusion can also be the result of similarities in backscatter response between the forest class and forested peatlands, which were merged with the general peatland class due to their small size and elongated shape. Open water is usually easily distinguishable in SAR imagery due to its 
specular reflectance properties (Baghdadi et al., 2001). The moderate classification accuracy in this study may be explained by the small size and dynamic nature of waterbodies in the region. This, together with the temporal gap between SAR and reference data (aerial photography) collection in which waterbodies may have changed shape (e.g., due to erosion along shorelines or permafrost thawing), are likely causes of confusion in the classification.

Table 7. Confusion matrix showing the Producer's and User's classification accuracies for the four land cover classes obtained from multi season SAR data.

\begin{tabular}{llllllll}
\hline Reference $\rightarrow$ & Producer's & User's & Open & Forest & Water & Peatland & Sum classified \\
Classified $\downarrow$ & accuracy & accuracy & upland & & & & \\
& $(\%)$ & $(\%)$ & & & & & \\
& & & & & & & \\
\hline Open upland & 84.1 & 83.6 & 963 & 58 & 24 & 100 & 1145 \\
Forest & 87.6 & 77.3 & 32 & 595 & 0 & 52 & 679 \\
Water & 96.5 & 89.2 & 7 & 2 & 330 & 3 & 342 \\
Peatland & 66.3 & 78.1 & 150 & 115 & 16 & 553 & 834 \\
\hline Sum reference & & & 1152 & 770 & 370 & 708 & 3000 \\
\hline
\end{tabular}

\subsection{Classification using LiDEM}

Terrain indices calculated from LiDEM, and combined with the SAR time series, substantially improved overall accuracy (90.9\%; Fig. 2), demonstrating the importance of topographic characteristics to distinguish land cover in this region. The same effect was also observed in the class specific accuracies, most of which were improved by approximately $5 \%$. The largest increase occurred in the peatland class where the Producer's and User's accuracies increased by 18.9 and 9.8 percentage points, respectively. The large increase in the Producer's accuracy resulted from a highly improved separation between the peatland and open upland classes, suggesting that the terrain indices do capture landscape features that control spatial 
variations of hydrological variability, in particular water flow, and the development of land cover types, such as peatland. A similar, but weaker, improvement occurred in the separation between the peatland and forest classes.

Table 8. Confusion matrix showing the Producer's and User's classification accuracies for the four land cover classes obtained from LiDEM+SAR.

\begin{tabular}{|c|c|c|c|c|c|c|c|}
\hline $\begin{array}{l}\text { Reference } \longrightarrow \\
\text { Classified } \downarrow\end{array}$ & $\begin{array}{l}\text { Producer's } \\
\text { accuracy } \\
(\%)\end{array}$ & $\begin{array}{l}\text { User's } \\
\text { accuracy } \\
\text { (\%) }\end{array}$ & $\begin{array}{l}\text { Open } \\
\text { upland }\end{array}$ & Forest & Water & Peatland & Sum classified \\
\hline Open upland & 91.6 & 92.5 & 1066 & 55 & 8 & 35 & 1164 \\
\hline Forest & 92.4 & 86.5 & 31 & 666 & 0 & 24 & 721 \\
\hline Water & 98.0 & 93.8 & 4 & 2 & 347 & 1 & 354 \\
\hline Peatland & 85.2 & 91.5 & 51 & 47 & 15 & 648 & 761 \\
\hline Sum reference & & & 1152 & 770 & 370 & 708 & 3000 \\
\hline
\end{tabular}

\subsection{Classification using ArcticDEM}

The results above demonstrate that terrain indices derived from LiDEM offer potential for distinguishing peatland areas compared to using SAR only, but its geographical coverage is limited and does not enable regional scale or pan-Arctic applications. The extensive geographic coverage is a main advantage of the ArcticDEM, which potentially makes it a key development in improving estimates of northern wetland extent.

Both the overall accuracy (87.5\%; Fig. 2) and class specific accuracies (Table 9) were considerably higher when terrain indices derived from ArcticDEM were used compared to the results from the SAR-only model, but marginally lower compared to the LiDEM+SAR classification. The ArcticDEM+SAR model confuses peatlands with open upland slightly more frequently than the LiDEM+SAR model. The specific reasons for this are difficult to 
isolate, but there are important differences between ArcticDEM and LiDEM in terms of input data used for production (stereo image matching vs. LiDAR), spatial resolution ( $5 \mathrm{~m}$ versus 2 $\mathrm{m})$, and thus in overall quality. In addition, ArcticDEM is a digital surface model that represents the elevation of all landscape features (e.g. trees, houses and power lines). LiDEM, on the other hand, is a higher-level product where the influence of natural and built landscape features have been removed and thus more accurately represents the bare Earth elevation. However, although the combination of SAR and LiDAR was superior, the combination of SAR and ArcticDEM was not far behind, which is promising for constraining northern circumpolar peatland area and distribution.

Table 9. Confusion matrix showing the Producer's and User's classification accuracies for the four land cover classes obtained from multi season SAR data and ArcticDEM.

\begin{tabular}{llllllll}
\hline Reference $\rightarrow$ & Producer's & User's & Open & Forest & Water & Wetland & Sum classified \\
Classified $\downarrow$ & accuracy & accuracy & upland & & & & \\
& $(\mathbf{\%})$ & $\mathbf{( \% )}$ & & & & & \\
& & & & & & & \\
\hline Open upland & 89.6 & 89.3 & $\mathbf{1 0 2 9}$ & 55 & 15 & 49 & 1148 \\
Forest & 90.2 & 82.2 & 34 & $\mathbf{6 3 3}$ & 0 & 35 & 702 \\
Water & 96.3 & 91.9 & 4 & 7 & $\mathbf{3 4 0}$ & 2 & 353 \\
Wetland & 78.0 & 87.9 & 85 & 75 & 15 & $\mathbf{6 2 2}$ & 797 \\
\hline Sum reference & & & 1152 & 770 & 370 & 708 & 3000
\end{tabular}

\subsection{Relationship between peatland size and classification accuracy}

Our results further show that the reliability of the classification method is partly dependent on peatland area size (Figure 3). When using the ArcticDEM+SAR model, the smallest size class (0.6-1 ha) has the largest error rate, where $40 \%$ of the peatland polygons had a proportion of correctly classified pixels below 50\%. The following size class (1-3 ha) had a slightly higher proportion of correctly classified pixels. The error rate stabilized for peatlands with a size of 
approximately $4-5$ ha. Above this size limit, more than $90 \%$ of the peatland polygons had a proportion of correctly classified pixels above $50 \%$. For the peatland polygons $>5$ ha, which represents $86.9 \%$ of the total peatland area according to the reference land cover map, the mean proportion of correctly classified pixels was $74 \%$.

The limited ability to resolve small peatlands is likely an effect of the input data resolution resulting from SAR speckle filtering, the spatial scales used for calculation of TI and the kernel size used in the post-processing regularization. A key topic for future research is to identify the optimal scales at which to perform these pre-processing steps. Such research should target northern latitude areas with different peatland characteristics and distribution, as well as different landscape topography and composition, with the aim to facilitate regional scale peatland mapping.

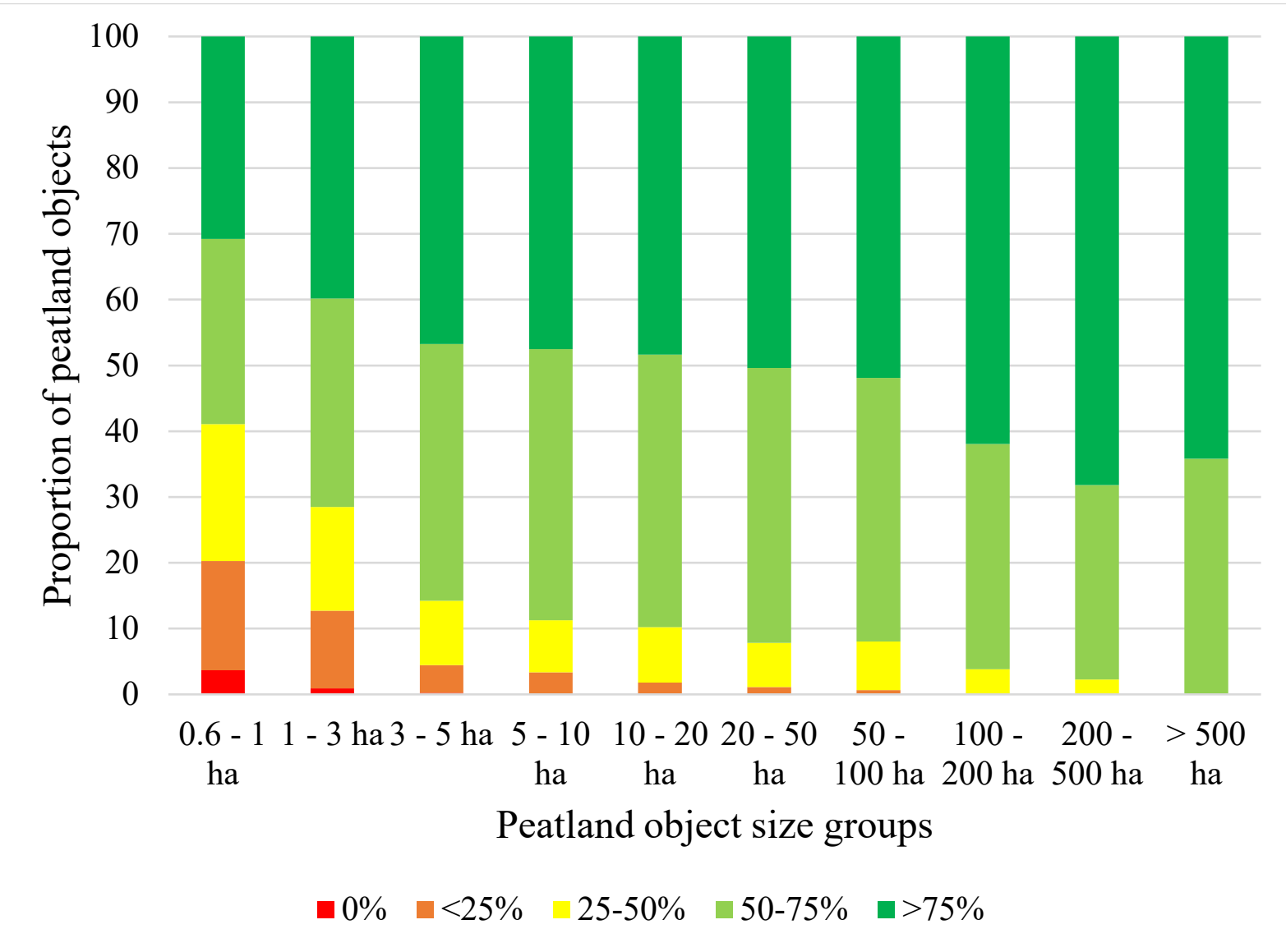


Figure 3. Classification accuracy in peatland size groups. The colour represent the proportion of correctly classified pixels within individual peatland objects.

\subsection{Importance of predictors}

The RF function of quantifying the contribution of each predictor to the classification, based on the mean decrease in accuracy criterion, provided a means to gain insights into the classification models. The results from this assessment show that the high resolution DEMs provide several of the high-ranking predictors (Fig. 4). It also clearly shows that the size of the local neighborhood used in the terrain index calculation is an important factor to consider in the DEM processing. Specifically, terrain indices derived from $30 \times 30$ pixel window clearly outperformed the smaller window size $(7 \times 7$ pixels $)$ in terms of predictor importance. While the results concerning window size are far from exhaustive, they provide an indication of the scale at which topographic variations become relevant for characterizing the land cover classes in focus of this study. The multi-scale elevation residual index (MERI) was identified as the most important predictor in this study. MERI does not require a predefined neighborhood size. Instead MERI characterizes the relative landscape position of a location (i.e. how elevated a location is compared with the surrounding) by considering multiple spatial scales, where the largest scale is determined by the size of the input DEM (Lindsay et al., 2015). Several studies of northern latitudes have included traditional surface derivatives, in particular slope, as a mean to improve classification accuracy with different levels of success (Corcoran et al., 2013; Guo et al., 2017). Our results suggest that several terrain indices have a higher potential to characterize land cover classes compared to slope in this environment, especially peatland areas.

The predictor importance assessment also clearly showed that the VH polarization outperformed the VV polarization in terms of contributing to the classification accuracy (Fig. 4). These results support previous findings on the suitability of $\mathrm{VH}$ polarization to distinguish 
boreal land cover (Baghdadi et al., 2001), especially in cases when $\mathrm{HH}$ polarization is not available, which is the case for Sentinel-1. On the other hand, it is more difficult to draw conclusions about the optimal season to acquire SAR imagery since several of the acquisition dates contribute approximately the same to the classification models. There can be large differences in surface conditions resulting from geographic variations in precipitation and temperature (e.g. seasonal changes take place at different times depending on microclimate and local wetness) which can influence the SAR signal and the classification results (Bartsch et al., 2012; Merchant et al., 2017). In such cases, inclusion of multiple SAR acquisitions might improve classification accuracy substantially by including information about seasonal changes and microclimatic conditions. In addition, peatlands in this area generally produce low C-band VH backscatter values during summer months due to their permanent wetness, compared to other land cover classes (Widhalm et al., 2015). On the other hand, the winter backscatter increases when peatlands are frozen or covered by snow (Naeimi et al., 2012). The relatively large seasonal backscatter differences in peatlands and open water may explain the similar contribution of summer and winter acquisitions (Bartsch et al., 2012).

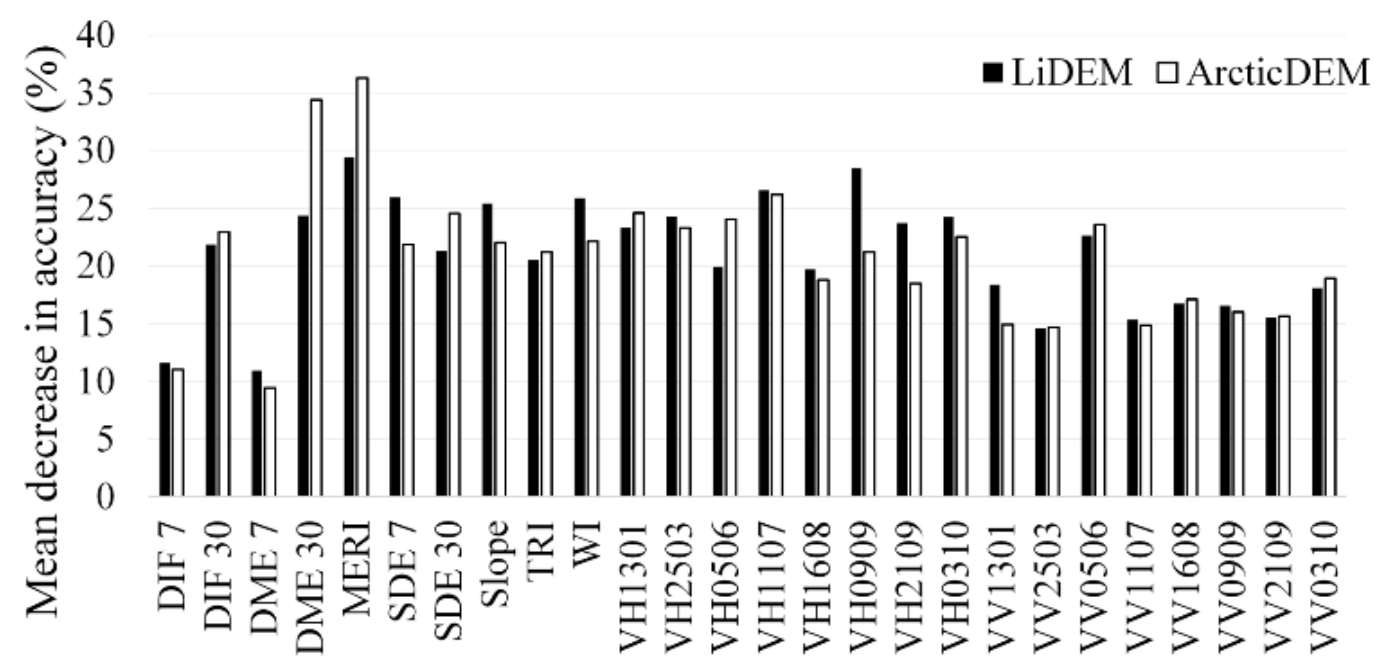

Predictor variables

Figure 4. Predictor importance based on the mean decrease in accuracy criterion. 


\subsection{Wetland area comparison and spatial distribution}

To further assess the ability of the three classification models to distinguish peatlands, the total peatland area derived from each classification was compared to three well-known land cover products, including the Swedish National Land Survey (SNLS) dataset, the CORINE land cover product and the Copernicus high-resolution wetlands layer (CHRW). The SNLS dataset is based on visual interpretation of aerial photography and includes the finest level of detail at the highest classification accuracy, whereas CORINE and CHRW are derived from medium resolution satellite imagery. Among the three classification models developed in this study, the SAR-only model appeared to overestimate peatland area when compared to the LiDEM+SAR and ArcticDEM+SAR models, as well as the other land cover products (Table 10). The peatland estimates of SNLS, LiDEM+SAR and ArcticDEM+SAR products were closest to each other $(<14 \%$ difference in estimated peatland area), with SNLS yielding the lowest and SAR+ArcticDEM yielding the highest area estimate of the three (Table 10). The CORINE and CHRW products were considerably lower $(24 \%$ and $32 \%$ less peatland area than SNLS, respectively; Table 10) and appear to underestimate the peatland area in this region. This is not surprising as products with lower spatial resolution is likely to miss many of the smaller peatland areas in the landscape mosaic. These results suggest that substantially improved regional scale estimates of northern peatland area can be achieved through a relatively simple synergetic application of Sentinel-1 and regional DEM.

Table 10. Comparison of wetland area between land cover products and classification models.

\section{Products and classification models $\quad$ Peatland area $\left(\mathrm{km}^{2}\right)$}

Swedish National Land Survey (SNLS) 3304

CORINE Land Cover

Copernicus High Resolution Wetlands (CHRW) 2251 
Difference maps calculated from the results of the three classification models developed in this study provide a different perspective on classification accuracy by showing large spatial variations in the resulting maps and providing indications where in the landscape misclassifications are most likely to occur. The SAR-only model misclassified large areas of bare land and forest located on hillsides as peatland (Fig. 5). The inclusion of terrain indices reduced this misclassification substantially by taking the spatial context of locations into account. Whereas this advantageous effect was strongest for the LiDEM+SAR model, an important improvement resulted from the ArcticDEM+SAR model. In addition, the SAR-only model tended to produce a considerably higher number of isolated peatland patches, whereas the terrain indices from both DEMs generally enabled a smother classification with homogeneous clustering of the classes, producing a more realistic land cover classification. 


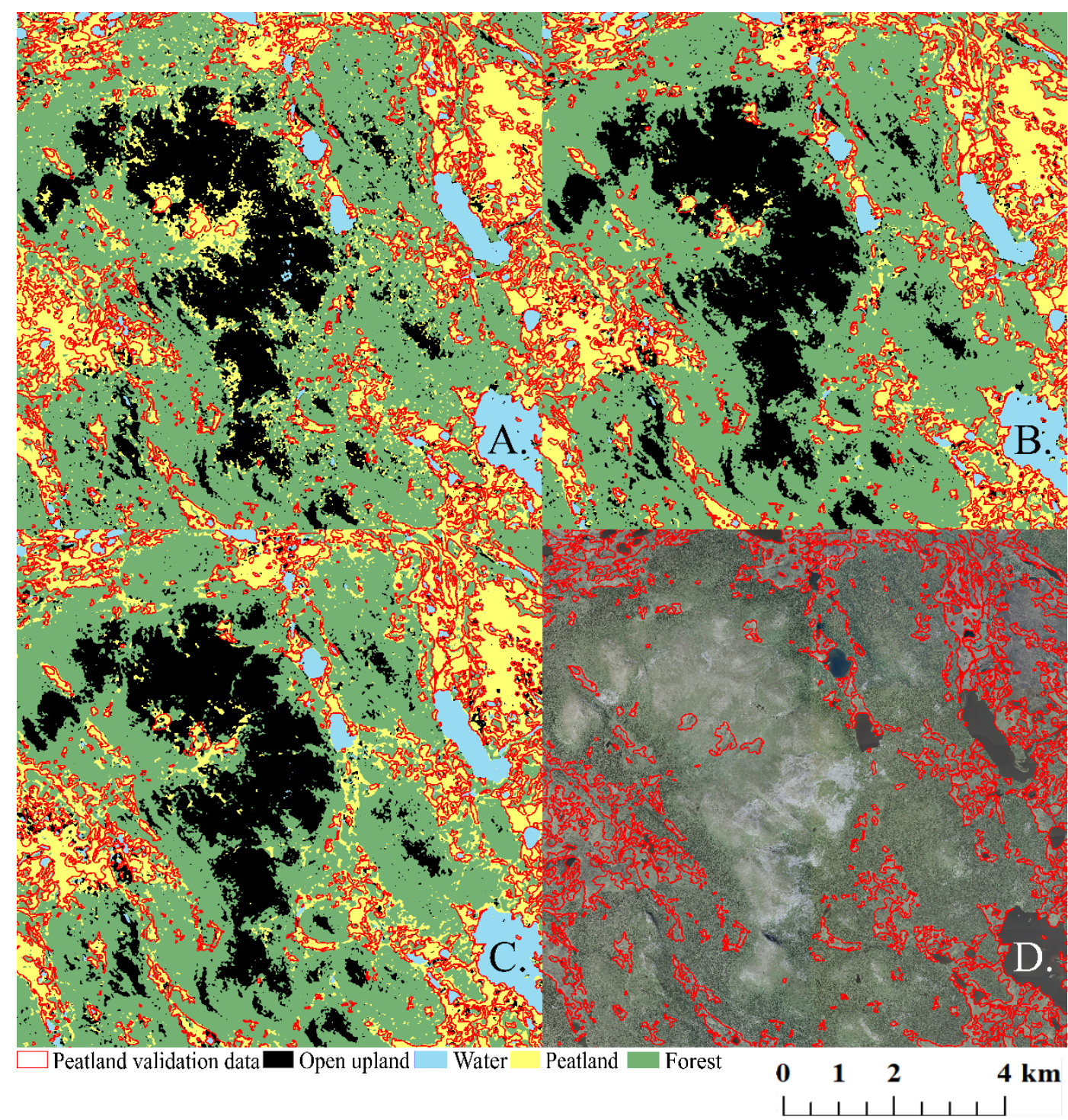

Figure 5. Image subset of a high-density peatland region in northern Sweden, produced using the three classification models SAR-only (A; 81.6\% overall accuracy, 0.77 kappa coefficient), LiDEM+SAR (B; 90.9\% overall accuracy, 0.87 kappa coefficient), ArcticDEM+SAR (C; $87.5 \%$ overall accuracy, 0.82 kappa coefficient), and aerial photography with peatland reference polygons (D).

\section{Conclusions}

Large uncertainties in the spatial extent, distribution and temporal dynamics of northern latitude land cover, in particular peatlands, impede progress in the understanding of several fundamental biogeochemical processes and cycles. Improved methods that enable efficient 
and accurate mapping of these complex landscape mosaics at high spatial and temporal resolution are therefore urgently needed. In this study, we investigated the capability of two new high resolution datasets that allow regional scale land cover mapping in northern latitude areas, the Sentinel-1 time-series and ArcticDEM.

Our results show that Sentinel-1 C-band SAR has potential to discriminate between most of the broad land cover classes defined in this study. Target classification was most successful with the identification of water, forest and open upland. However, significant limitations were observed for the peatland class, which was often confused with open upland areas, possibly due to the dual-polarized configuration of Sentinel-1 and the lack of $\mathrm{HH}$ polarization. The use of multi-temporal SAR acquisitions can compensate for this inherent limitation to some extent, albeit at the cost of substantially increased data processing needs. Another potential cause of low classification accuracy is local variations in environmental and weather conditions throughout the relatively large study area known to influence the SAR signal.

Classification accuracy improved substantially by combing terrain indices derived from LiDEM and ArcticDEM with multi-temporal SAR. The largest improvement was obtained for the peatland class, which suggests that many of the terrain indices are able to characterize topographic features in the landscape with a strong linkage to wetland formation. When compared to LiDEM, ArcticDEM obtained similar classification accuracy in the test area. This is an encouraging finding considering the regional coverage of ArcticDEM and current information needs about land cover extent and temporal dynamics in this challenging landscape type.

Further assessments of the datasets and methods used in this study should be conducted in other peatland-dominated landscapes in northern latitude areas. In order to facilitate regional scale application, forthcoming research should also focus on strategies to reduce input data 
volume and processing requirements. Key issues include optimizing spatial resampling, as well as developing strategies for SAR image acquisitions and terrain index calculations.

Accurate delineation of peatlands throughout the Arctic over time would allow major progress in quantifying e.g. water, carbon and greenhouse gas balances, and effects of climate change. Furthermore, all of this would benefit from a detailed separation of peatland types more closely linked to specific processes, including transitions in vegetation composition and soil water dynamics. The delineation of peatlands provides an important step towards constraining overall peatland areas and for future efforts to map different wetland types.

\section{Acknowledgement}

This study was funded by a grant from the Swedish Research Council VR to David Bastviken (ref. no. VR 2012-48), by the IZOMET project (ref. no. VR 2014-6584), and by a grant from the Swedish research Council for Sustainable Development (Formas; ref. no. 2018-00570) to Martin Karlson.

\section{References}

Ågren, A.M., Lidberg, W., Strömgren, M., Ogilvie, J., Arp, P.A., 2014. Evaluating digital terrain indices for soil wetness mapping - a Swedish case study. Hydrol. Earth Syst. Sci. 18, 3623-3634. https://doi.org/10.5194/hess-18-3623-2014

Amani, M., Salehi, B., Mahdavi, S., Granger, J., Brisco, B., 2017. Wetland classification in Newfoundland and Labrador using multi-source SAR and optical data integration. GIScience Remote Sens. 54, 779-796. https://doi.org/10.1080/15481603.2017.1331510

Baghdadi, N., Bernier, M., Gauthier, R., Neeson, I., 2001. Evaluation of C-band SAR data for wetlands mapping. Int. J. Remote Sens. 22, 71-88. https://doi.org/10.1080/014311601750038857 
Bartsch, A., Hofler, A., Kroisleitner, C., Trofaier, A.M., 2016. Land cover mapping in northern high latitude permafrost regions with satellite data: achievements and remaining challenges. Remote Sens. 8, 979. https://doi.org/10.3390/rs8120979

Bartsch, A., Trofaier, A.M., Hayman, G., Sabel, D., Schlaffer, S., Clark, D.B., Blyth, E., 2012. Detection of open water dynamics with ENVISAT ASAR in support of land surface modelling at high latitudes. Biogeosciences 9, 703-714. https://doi.org/10.5194/bg-9-703-2012

Belgiu, M., Drăguţ, L., 2016. Random forest in remote sensing: A review of applications and future directions. ISPRS J. Photogramm. Remote Sens. 114, 24-31. https://doi.org/https://doi.org/10.1016/j.isprsjprs.2016.01.011

Beven, K.J., Kirby, M.J., 1979. A physically based, variable contributing area model of basin hydrology. Hydrol. Sci. Bull. 24, 43-69.

Breiman, L., 2001. Random Forests. Mach. Learn. 45, 5-32. https://doi.org/10.1023/A:1010933404324

Brisco, B., Kapfer, M., Hirose, T., Tedford, B., Liu, J., 2011. Evaluation of C-band polarization diversity and polarimetry for wetland mapping. Can. J. Remote Sens. 37, 82-92. https://doi.org/10.5589/m11-017

Clewley, D., Whitcomb, J., Moghaddam, M., McDonald, K., Chapman, B., Bunting, P., 2015. Evaluation of ALOS PALSAR data for high-resolution mapping of vegetated wetlands in Alaska. Remote Sens. 7, 7272-7297. https://doi.org/10.3390/rs70607272

Cohen, J., 1960. A coefficient of agreement for nominal scales. Educ. Psychol. Meas. 20, 37 46.

Corcoran, M.J., Knight, F.J., Gallant, L.A., 2013. Influence of multi-source and multi- 
temporal remotely sensed and ancillary data on the accuracy of Random Forest classification of wetlands in northern Minnesota. Remote Sens. https://doi.org/10.3390/rs5073212

Costa, M.P.F., 2004. Use of SAR satellites for mapping zonation of vegetation communities in the Amazon floodplain. Int. J. Remote Sens. 25, 1817-1835. https://doi.org/10.1080/0143116031000116985

de Almeida Furtado, L.F., Silva, T.S.F., de Moraes Novo, E.M.L., 2016. Dual-season and full-polarimetric $\mathrm{C}$ band SAR assessment for vegetation mapping in the Amazon várzea wetlands. Remote Sens. Environ. 174, 212-222. https://doi.org/https://doi.org/10.1016/j.rse.2015.12.013

ESA, 2017. SNAP - ESA Sentinel Application Platform v5.0.

Franzén, L.G., 1985. Peat in Sweden - a method to calculate the resources. University of Gothenburg.

Frey, K.E., Smith, L.C., 2007. How well do we know northern land cover? Comparison of four global vegetation and wetland products with a new ground-truth database for West Siberia. Global Biogeochem. Cycles 21. https://doi.org/10.1029/2006GB002706

Gallant, J.C., Wilson, J.P., 2000. Primary topographic attributes, in: Wilson, J.P., Gallant, J.C. (Eds.), Terrain Analysis: Principles and Applications. John Wiley, Hoboken, New Jersey, pp. 51-85.

Guo, M., Li, J., Sheng, C., Xu, J., Wu, L., 2017. A review of wetland remote sensing. Sensors. https://doi.org/10.3390/s17040777

Hess, L.L., Melack, J.M., Affonso, A.G., Barbosa, C., Gastil-Buhl, M., de Moraes Novo, E.M.L., 2015. Wetlands of the lowland Amazon basin: extent, vegetative cover, and 
dual-season inundated area as mapped with JERS-1 synthetic aperture radar. Wetlands 35, 745-756. https://doi.org/10.1007/s13157-015-0666-y

Hess, L.L., Melack, J.M., de Moraes Novo, E.M.L., Barbosa, C.C.F., Gastil, M., 2003. Dualseason mapping of wetland inundation and vegetation for the central Amazon basin. Remote Sens. Environ. 87, 404-428. https://doi.org/https://doi.org/10.1016/j.rse.2003.04.001

Hess, L.L., Melack, J.M., Filoso, S., Wang, Y., 1995. Delineation of inundated area and vegetation along the Amazon floodplain with the SIR-C synthetic aperture radar. IEEE Trans. Geosci. Remote Sens. 33, 896-904. https://doi.org/10.1109/36.406675

Higginbottom, T.P., Field, C.D., Rosenburgh, A.E., Wright, A., Symeonakis, E., Caporn, S.J.M., 2018. High-resolution wetness index mapping: A useful tool for regional scale wetland management. Ecol. Inform. 48, 89-96. https://doi.org/https://doi.org/10.1016/j.ecoinf.2018.08.003

Horn, B., 1981. Hill shading and the reflectance map. Proc. IEEE 69, 14-47.

Hu, S., Niu, Z., Chen, Y., 2017. Global wetland datasets: a review. Wetlands 37, 807-817. https://doi.org/10.1007/s13157-017-0927-z

Ireson, A.M., Barr, A.G., Johnstone, J.F., Mamet, S.D., van der Kamp, G., Whitfield, C.J., Michel, N.L., North, R.L., Westbrook, C.J., DeBeer, C., Chun, K.P., Nazemi, A., Sagin, J., 2015. The changing water cycle: the Boreal Plains ecozone of Western Canada. WIREs Water 2, 505-521.

Karlson, M., Ostwald, M., Reese, H., Bazié, H.R., Tankoano, B., 2016. Assessing the potential of multi-seasonal WorldView-2 imagery for mapping West African agroforestry tree species. Int. J. Appl. Earth Obs. Geoinf. 50, 80-88. 
https://doi.org/https://doi.org/10.1016/j.jag.2016.03.004

Karlson, M., Ostwald, M., Reese, H., Sanou, J., Tankoano, B., Mattsson, E., 2015. Mapping tree canopy cover and aboveground biomass in Sudano-Sahelian woodlands using Landsat 8 and random forest. Remote Sens. 7, 10017-10041. https://doi.org/10.3390/rs70810017

Kirschke, S., Bousquet, P., Ciais, P., Saunois, M., Canadell, J.G., Dlugokencky, E.J., Bergamaschi, P., Bergmann, D., Blake, D.R., Bruhwiler, L., Cameron-Smith, P., Castaldi, S., Chevallier, F., Feng, L., Fraser, A., Heimann, M., Hodson, E.L., Houweling, S., Josse, B., Fraser, P.J., Krummel, P.B., Lamarque, J.-F., Langenfelds, R.L., Le Quéré, C., Naik, V., O’Doherty, S., Palmer, P.I., Pison, I., Plummer, D., Poulter, B., Prinn, R.G., Rigby, M., Ringeval, B., Santini, M., Schmidt, M., Shindell, D.T., Simpson, I.J., Spahni, R., Steele, L.P., Strode, S.A., Sudo, K., Szopa, S., van der Werf, G.R., Voulgarakis, A., van Weele, M., Weiss, R.F., Williams, J.E., Zeng, G., 2013. Three decades of global methane sources and sinks. Nat. Geosci. 6, 813.

Krankina, O.N., Pflugmacher, D., Friedl, M., Cohen, W.B., Nelson, P., Baccini, A., 2008. Meeting the challenge of mapping peatlands with remotely sensed data. Biogeosciences 5, 1809-1820. https://doi.org/10.5194/bg-5-1809-2008

Lang, M., McCarty, G., Oesterling, R., Yeo, I.-Y., 2013. Topographic metrics for improved mapping of forested wetlands. Wetlands 33, 141-155. https://doi.org/10.1007/s13157012-0359-8

Lantmäteriet, 2015a. Produktbeskrivning: GSD-Terrängkartan, vektor.

Lantmäteriet, 2015b. Produktbeskrivning: GSD-Höjddata, grid 2+.

Lantmäteriet, 2015c. Produktbeskrivning: GSD-Ortofoto och GSD-Ortofoto 25. 
Liaw, A., Wiener, M., 2002. Classification and regression by randomForest. R J. 2, 118-122.

Lindsay, J.B., 2016. Whitebox GAT: A case study in geomorphometric analysis. Comput. Geosci. 95, 75-84. https://doi.org/https://doi.org/10.1016/j.cageo.2016.07.003

Lindsay, J.B., Cockburn, J.M.H., Russell, H.A.J., 2015. An integral image approach to performing multi-scale topographic position analysis. Geomorphology 245, 51-61. https://doi.org/https://doi.org/10.1016/j.geomorph.2015.05.025

Mahdianpari, M., Salehi, B., Mohammadimanesh, F., Motagh, M., 2017. Random forest wetland classification using ALOS-2 L-band, RADARSAT-2 C-band, and TerraSAR-X imagery. ISPRS J. Photogramm. Remote Sens. 130, 13-31. https://doi.org/https://doi.org/10.1016/j.isprsjprs.2017.05.010

McGuire, A.D., Anderson, L.G., Christensen, T.R., Dallimore, S., Guo, L., Hayes, D.J., Heimann, M., Lorenson, T.D., Macdonald, R.W., Roulet, N., 2009. Sensitivity of the carbon cycle in the Arctic to climate change. Ecol. Monogr. 79, 523-555. https://doi.org/10.1890/08-2025.1

Melton, J.R., Wania, R., Hodson, E.L., Poulter, B., Ringeval, B., Spahni, R., Bohn, T., Avis, C.A., Beerling, D.J., Chen, G., Eliseev, A. V, Denisov, S.N., Hopcroft, P.O., Lettenmaier, D.P., Riley, W.J., Singarayer, J.S., Subin, Z.M., Tian, H., Zürcher, S., Brovkin, V., van Bodegom, P.M., Kleinen, T., Yu, Z.C., Kaplan, J.O., 2013. Present state of global wetland extent and wetland methane modelling: conclusions from a model inter-comparison project (WETCHIMP). Biogeosciences 10, 753-788. https://doi.org/10.5194/bg-10-753-2013

Merchant, M.A., Adams, J.R., Berg, A.A., Baltzer, J.L., Quinton, W.L., Chasmer, L.E., 2017. Contributions of C-band SAR data and polarimetric decompositions to subarctic boreal peatland mapping. IEEE J. Sel. Top. Appl. Earth Obs. Remote Sens. 10, 1467-1482. 
https://doi.org/10.1109/JSTARS.2016.2621043

Millennium Ecosystem Assessment, 2005. Ecosystems and human well being: synthesis. Island Press, Washington DC.

Naeimi, V., Paulik, C., Bartsch, A., Wagner, W., Kidd, R., Park, S., Elger, K., Boike, J., 2012. ASCAT Surface State Flag (SSF): Extracting Information on Surface Freeze/Thaw Conditions From Backscatter Data Using an Empirical Threshold-Analysis Algorithm. IEEE Trans. Geosci. Remote Sens. 50, 2566-2582. https://doi.org/10.1109/TGRS.2011.2177667

O'Callaghan, J.F., Mark, D.M., 1984. The extraction of drainage networks from digital elevation data. Comput. Vis. Graph. Image Process. 27, 323-344.

Ozesmi, S.L., Bauer, M.E., 2002. Satellite remote sensing of wetlands. Wetl. Ecol. Manag. 10, 381-402. https://doi.org/10.1023/A:1020908432489

Pelletier, C., Valero, S., Inglada, J., Champion, N., Dedieu, G., 2016. Assessing the robustness of Random Forests to map land cover with high resolution satellite image time series over large areas. Remote Sens. Environ. 187, 156-168. https://doi.org/https://doi.org/10.1016/j.rse.2016.10.010

Pflugmacher, D., Krankina, O.N., Cohen, W.B., Friedl, M.A., Sulla-Menashe, D., Kennedy, R.E., Nelson, P., Loboda, T. V, Kuemmerle, T., Dyukarev, E., Elsakov, V., Kharuk, V.I., 2011. Comparison and assessment of coarse resolution land cover maps for Northern Eurasia. Remote Sens. Environ. 115, 3539-3553. https://doi.org/https://doi.org/10.1016/j.rse.2011.08.016

R Development Core Team, 2013. R: A language and environment for statistical computing. $\mathrm{R}$ foundation for statistical computing, Vienna. 
Reschke, J., Bartsch, A., Schlaffer, S., Schepaschenko, D., 2012. Capability of C-band SAR for operational wetland monitoring at high latitudes. Remote Sens. 4, 2923-2943. https://doi.org/10.3390/rs4102923

Riley, S.J., DeGloria, S.D., Elliot, R., 1999. A terrain ruggedness index that quantifies topographic heterogeneity. Intermt. J. Sci. 5, 23-27.

Rundquist, D.C., Narumalani, S., Narayanan, R.M., 2001. A review of wetlands remote sensing and defining new considerations. Remote Sens. Rev. 20, 207-226. https://doi.org/10.1080/02757250109532435

Silva, T.S.F., Melack, J.M., Streher, A., Ferreira-Ferreira, J., Furtado, L.F.A., 2015. Capturing the dynamics of Amazonian wetlands using synthetic aperture radar: lessons learned and future directions, in: Remote Sensing of Wetlands. CRC Press, pp. 455-472.

Tockner, K., Pennetzdorfer, D., Reiner, N., Schiemer, F., Ward, J. V, 2001. Hydrological connectivity, and the exchange of organic matter and nutrients in a dynamic riverfloodplain system (Danube, Austria). Freshw. Biol. 41, 521-535. https://doi.org/10.1046/j.1365-2427.1999.00399.x

Torbick, N., Persson, A., Olefeldt, D., Frolking, S., Salas, W., Hagen, S., Crill, P., Li, C., 2012. High Resolution Mapping of Peatland Hydroperiod at a High-Latitude Swedish Mire. Remote Sens. 4, 1974-1994. https://doi.org/10.3390/rs4071974

Töyrä, J., Pietroniro, A., 2005. Towards operational monitoring of a northern wetland using geomatics-based techniques. Remote Sens. Environ. 97, 174-191. https://doi.org/10.1016/j.rse.2005.03.012

Whitcomb, J., Moghaddam, M., McDonald, K., Kellndorfer, J., Podest, E., 2009. Mapping vegetated wetlands of Alaska using L-band radar satellite imagery. Can. J. Remote Sens. 
35, 54-72. https://doi.org/10.5589/m08-080

White, L., Brisco, B., Dabboor, M., Schmitt, A., Pratt, A., 2015. A collection of SAR methodologies for monitoring wetlands. Remote Sens. 7, 7615-7645. https://doi.org/10.3390/rs70607615

Widhalm, B., Bartsch, A., Heim, B., 2015. A novel approach for the characterization of tundra wetland regions with C-band SAR satellite data. Int. J. Remote Sens. 36, 55375556. https://doi.org/10.1080/01431161.2015.1101505

Wieder, R.., Vitt, D.. (Eds.), 2006. Boreal Peatland Ecosystems, 1st ed. Springer-Verlag, Berlin Heidelberg.

Wright, C., Gallant, A., 2007. Improved wetland remote sensing in Yellowstone National Park using classification trees to combine TM imagery and ancillary environmental data. Remote Sens. Environ. 107, 582-605.

https://doi.org/https://doi.org/10.1016/j.rse.2006.10.019

\section{LIST OF FIGURE CAPTIONS}

Figure 1. Left: Map showing the Nordic countries and the study area in northern Sweden. Right: Sentinel-1 backscatter mosaic (VH polarization) of the study area on July 11, 2016.

Figure 2. Overall classification accuracy (\%) and Kappa statistic values produced by three classification models.

Figure 3. Classification accuracy in peatland size groups. The colour represent the proportion of correctly classified pixels within individual peatland objects.

Figure 4. Predictor importance based on the mean decrease in accuracy criterion.

Figure 5. Image subset of a high-density peatland region in northern Sweden, produced using the three classification models SAR-only (A; 81.6\% overall accuracy, 0.77 kappa coefficient), 
LiDEM+SAR (B; 90.9\% overall accuracy, 0.87 kappa coefficient), ArcticDEM+SAR (C; $87.5 \%$ overall accuracy, 0.82 kappa coefficient), and aerial photography with peatland reference polygons (D). 